Mr. Watkins, in moving the next resolution, said, before he made any remarks, he would read it:-

Resolved-

"That this meeting is of opinion that the provisions of the Bill should be such as to impress upon the profession, in all its branches, a scientific character, and to discourage a trading principle, which tends to degrade the profession to the level of quackery. The meeting is also of opinion that the sale of patent medicines ought to be discouraged by the Government, and not made an object of revenue."

He (Mr. W.) said that the shopkeeping system had a tendency to degrade the profession. He remarked, that if the qualified medical man will trespass on the domain of the chemist and druggist, the former can scarcely complain of the adoption of the only means of retaliation within the reach of injured parties. In conclusion, he begged of the meeting to express its disapprobation of this principle, by carrying the resolution without a dissentient roice. (Cheers.)

Mr. Pretry seconded the resolution, which was carried unanimously.

Mr. Sutheris rose to propose the next resolution, which was, that the names of certain gentlemen be appointed to form a committee, for the purpose of carrying the preceding excellent resolutions into effect. He trusted that no one would accuse him of partiality when he informed them that he had exerted no influence whatever in framing that committee, but that he conscientiously believed the gentlemen had been chosen, independent of faction, entirely from their standing in the College; he therefore hoped that no opposition would be offered to his motion. He concluded by reading the following resolution-viz.

"That a committee be formed, consisting of Messrs. Routh, Meeson, Teague, Wood, Kempthorne, Kemp, Colborne, Newton, and Mussabini, with power to add to their numbers, for the purpose of framing a petition based upon the preceding resolutions, and that Thomas Wakley, Esq. M,P., be requested to present the same to the House of Commons." (Cheers.)

Mr. Mardens seconded the resolution, which was carried.

Mr. Woop rose to propose the next resolution. He said, that if he had thought that any discussion whatever was likely to arise on it, he should certainly have shrunk from the task, and yielded it at once into the hands of some one more competent than he was to advocate it as its merits deserve. But feeling, as he did, that it was no small privilege to be called upon to propose that resolution; feeling, as he did, that without it their proceedings would be not only incomplete, but ungrateful, he did not hesitate for one moment to appear before them on that occasion. (Hear, hear.) The resolution was-

"That the thanks of this meeting be given to Thomas Wakley, Esq. M.P., Editor of THE LANCET, and to the Editor of The Times newspaper, for their able defence of the rights and privileges of the medical profession, and that the Editor of Tra LANCET be requested to insert a report of the proceedings of this meeting in that journal at the earliest convenient time." (Loud cheers.)

The resolution had been received as he knew it would be, by a large, intelligent, and influential body of medical students. What had the Editor of THE LANCET not done to promote their interests? (Hear, hear.) Before the establishment of that journal, there were no clinical lectures delivered in the hospitals of the metropolis, and the proceedings of the various medical societies were never made public. How different the case was now, any one there present could testify. (Loud cheering.) By a reference to the pages of that journal, a student could, at a glance, perceive what direction the medical mind was taking, not in England only, but in Europe. (Hear, hear.) But let them turn from scientific to political services. The Editor of THE LANCET might truly be styled the Father of Medical Reform. (Cheers.) He had laboured in the cause for more than twenty years, and now that victory seemed about to crown his efforts, it did seem meet and right in those for whom he had fought and conquered to return him their cordial and grateful acknowledgments. (Loud and continued cheering.) To him they owed the enunciation of the great principle of representative government. Oh ! what a mockery it was, that in the same breath in which they were pronounced fit to practise surgery in all its branches, and to undertake a case involving life and death, they were declared incompetent to elect those who were to regulate the expenditure of the funds with which they (the students) had furnished them (Hear, hear.) He need only allude to the steady and persevering advocacy by THE LANCET of the election to public offices by " concours," and its determined opposition to quackery in all its forms. (Loud cheers.) With feelings of confidence, then, did he call upon them to pass that resolution as they had passed the others-unanimously; showing to the world, that although others, whose names had never been heard in connexion with medical reform till within the last few months, might now step in and claim the victory, medical students, at least, would know to whom the credit was due, and would give to Mr. Wakley their cordial, grateful. and well-merited thanks. (Loud and prolonged cheering.)

Mr. TEague seconded this resolution, which was carried amidst deafening shouts of applause.

After a vote of thanks to the chairman, the meeting dispersed.

\section{ROYAL COLLEGE OF SURGEONS OF ENGLAND} AND THE

PERMANEN'T COMMITTEE OF THE

NATIONAL ASSOCIATION OF GENERAL PRACTITIONERS IN MEDICINE, SURGERY, AND MIDWIFERY.

To the President, Vice-Presidents, and Council of the Royal College of Surgeons of England.

Gentremen, - We are requested by the Committee of the National Association to forward you a copy of the following resolution, unanimously passed at a very numerous meeting of General Practitioners, held at the Hanover-square Rooms, on Friday, the 14th of March:-

Resolved "That the National Association records its solemn protest against the proceedings of the Council of the College of Surgeons, in obtaining, and in subsequently carrying out, the recent charter, whereby a few gentlemen have been arbitrarily elevated over the heads of others previously their equals in professional rank-senior to many of them as members of the College, and not inferior to most of them in scientific and practical knowledge."

And, in compliance with a suggestion offered by the Right Hon. Sir James Graham to a deputation of the National Association, on the 14th of February, to request the favour of an early answer to the following inquiries:-

1. Is the Council of the College prepared to reconsider their charter, and to place those members who were in practice before it was granted, on a level with the fellows?

2. Is the Council of the College disposed to admit to its hoard a fair representation of the members of the College in general practice?

3. Would the Council of the College be willing to co-operate with the National Association in the formation of a Court of Examiners in medicine, surgery, and midwifery?

And as a further duty has now devolved upon the Committee, by a resolution of the general meeting, "to use every practical means to obtain a charter of incorporation for the general practitioners," they are desirous to ascertain how far, and in what manner, the Council of the College of Surgeons may be disposed to assist the National Association in the attainment of its object.

Should the Council be pleased to entertain these propositions, the Committee will be happy to appoint a deputation of its members for the purpose of an early conference, on a subject so important to the best interests of the profession and the public.

We have the honour to remain, gentlemen,

\section{Your most obedient servants,}

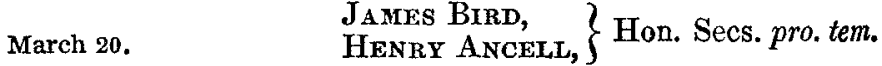

To the Secretaries of the National Association of General Practitioners \&c.

Gentumes, - The Council of the Royal College of Surgeons of England have the honour to acknowledge your letter of the 20 th of March.

It exhibits, first, a resolution of the gentlemen styling themselves the National Association-viz., "That the National Association records its solemn protest against the proceedings of the Council of the College of Surgeons, in obtaining, and in subsequently carrying out, the recent charter, whereby a few gentlemen have been arbitrarily elevated over the heads of others, previously their equals in professional rank, senior to many of them as members of the College, and not inferior to most of them in scientific and practical knowledge."

It next recites three questions-viz., First-_" Is the Council of the College prepared to reconsider their charter, and to place those members who were in practice before it was granted on a level with the fellows?"

Second-" Is the Council of the College disposed to admit to its board a fair representation of the members of the College in general practice?"

Third-"Would the Council of the College be willing to cooperate with the National Association of General Practitioners in 
the formation of a Court of Examiners in medicine, surgery, and mid wifery?"

And the letter states, lastly, that " as a further duty has now devolved upon the Committee, by a resolution of the general meeting, 'to use every practicahle means to obtain a charter of incorporation for the general practitioners,' they are desirous to ascertain how far, and in what manner, the Council of the College of Surgeons may be disposed to assist the National Association in the attainment of its object."

Such is the substanee of the communication addressed to the Council of the Royal College of Surgeons, and though they might claim exemption from replying to propositions which can only legitimately emanate from the whole body, or at least from a majority of the practitioners, whose interests are involved, they willingly forego this plea, however valid, in finding connected with the National Association many members of the College, whom they individually esteem, and in deference to the highly respectable class from which the Association has been formed.

In noticing the protest of the National Association, the Council have to remark, that the formation of the new class of fellows was an obligation imposed upon them by her Majesty's Government, for the purpose of providing an electoral body. The principles on which they acted, in conformity with the provisions of the recent charter to that effect, are sufficiently explained in the following paragraphs, quoted from a statement, dated May 25, 1844, which was circulated among the members:-

"The Council entered on the duty assigned to them by the provisions of the charter, with a full sense of its invidious nature. They were aware that of those not included in the list of fellows a considerable number would feel and express dissatisfaction; but they have done what was required of them to the best of their ability, and have made the selection altogether on public grounds, without favour or prejudice, and uninfluenced by private motives. The great majority of the members of this college are less engaged in the practice of surgery than in that of medicine, midwifery, and pharmacy, and many of them have arrived at well-deserved eminence in these latter departments of the medical profession. But the Council, keeping in view the objects for which the College was especially established, have felt it their duty, in the nomination of fellows, to regard chiefly the qualifications of members as practitioners in surgery, or as improvers of those sciences which tend to its advancement."

This was the principle which guided the Council in discharging this responsible duty, publicly proposed and submitted to the opinion of the members of the College, whilst the power of nomination still remained; and the principle unhesitatingly avowed by the Council, as that upon which they acted, and upon which they feel bound to act, were they entrusted with the office of reconstructing the schedule of fellows, is that of the selection of those who have distinguished themselves by the cultivation of surgery and its collateral sciences.

If, then, the first question which the National Association proposes has reference to a reconsideration of the charter recestly granted exclusively for the purpose of placing all the members who were in practice before it was granted on the list of fellows, or, in other words of the letter, "on a level with the fellows," the Council earnestly protest against the scheme, as essentially contravening the principle which they deemed it their duty to adopt; and they profess themselves unable to understand the grounds of a proposal which, in their deliberate judgment, would, by the lavish and indiscriminate grant of the fellow ship, effectually destroy a distinction which, if conferred on all, would be no distinction, and could confer no honour on the individual possessor.

It is true, indeed, that the alleged injustice of elevating a limited number of the members to a higher professional rank than their colleagues would have been obviated, and that the twelve thousand or fourteen thousand members who might thus have been created fellows, would nominally possess a superior grade to those members admitted subsequently to September, 1843 ; but it is equally plain, that these newly-created fellows would not have obtained their rank by any authorized claim to superior surgical attainments, since their qualifications could only have been tested by examinations, which always have been, and must ever be, conducted on the principle imperiously demanded by the neeas of society-namely, that the majority of surgical practitioners shall be required. to possess at least but not necessarily more than, that amount of information and skill which is absolutely required for the ordinary exigencies of surgical ministrations.

The Council, therefore, under a sense of justice to their future members, who will possess the same qualification as the present members, and under the obligation which the institution of the novel honorary degree imposed, necessarily sought other evidence of distinguished surgical attainments than the ordinary diploma, which attests only the amount of proficiency required of all. And those who feel disappointment would do well to bear in mind that they have been deprived of no privileges nor corporate rights, which they acquired, or hoped to possess, in becoming members of the College. They will recollect that in applying for their diploma they were not compelled to do so by any legal enactment, as they would have had an equal right to practise surgery without it, and they will probably admit that their sole inducement was that of obtaining in the diploma a testimonial to which the names of some of the principal hospital surgeons and teachers were appended. And let them not forget that one of the first acts of the College was to make a by-law, which was sanctioned by the proper authorities, excluding practitioners in pharmacy and midwitery from the governing hody of the College, that they obtained their diploma under this known condition, and that they actually signed this and other by-lars, and swore to observe them.

It has been said and reiterated, as it is intimated in the protest of the Association, that the omission from the list of fellows implies professional degradation; the Council, however, cannot but think that this feeling is grounded on a misconception of the nature of the qualification for the fellowship, already explained. Many of those who have not been included in the list of fellows are well known to have attained the highest eminence, and to enjoy the highest reputation as practitioners in other departments of the profession; and the Council cannot believe that the interests, personal and professional, of members, can be injuriously affected, or their merits lowered in the estimation of the neighbourhood in which they reside, by the ricinity of those nominated as fellows, since the fellowship is simply an attestation of the surgical reputation which they already possessed ; and this distinction will be in a great degree effaced by the provisions of the medical Bill now under the consideration of the legislature; since, in conformity therewith, every member of the College may, if he please, be registered as a surgeon, whether he be in general practice or not, and may thus be presented to the public in the same list, and under the same title, with the president, councillors, and other feilows of the College.

The Council deeply regret that their motives should have been misconstrued, and that so many of the members of the College should disapprove of their proceedings, but they trust that a dispassionate reconsideration of the subject will not fail to con vince the Association that it would be difficult, if not impossible, to form a class of fellows, in which the requisite respectability of the class should be preserved, without adopting a principle of selection no less invidious than that which has drawn so much obloquy on the Council. It has been contended, and the principle has been more than once agitated in the discussions in the Council, that the senior members admitted antecedently to a given date should form wholly, or in part, the list of fellows. But where was the line to be drawn that would have been satisfactory to those excluded?

It has been also proposed, that as vacancies occurred the places might be supplied until all the members admitted before September, 1843, had been placed in succession on the list of fellows. But it behoves those who contend for any mode of forming a list upon the simple principle of seniority without selection, and still more those who urge the indiscriminate admission of all members to the fellowship, to weigh well the insurmountable objections to their scheme. Would they include those who have violated the laws of their country? Would they include professional paupers, and persons of notoriously bad character? Would they include the puffers and vendors of nostrums and secret remedies, and the writers of indecent advertisements? Would they include surgeons' assistants, or those who have connected themselves in business with druggists and chemists? Would they include the retail shopkeepers, who expose for sale cattle drugs and perfumery? Would they, finally, include or exclude all those who keep open shops, and who, though ill sustaining a professional character, are yet not chargeable with any moral disqualification. In short, would the National Association, in conformity with their views, advise admitting all such as members of the proposed college of general practitioners, without discrimination or selection, merely because they are members of the College of Surgeons, or licentiates of the Apothecaries' Company.

These are grave questions, which cannot be dismissed by a simple negative or affirmative, and would require for their solution nicer distinction than the Asssciation seems to have anticipated; and, on second thoughts, the Association may perhaps forgive the Council for ridding themselves of the difficulties attendant on the investigation of comparative respectability, by adopting a surgical qualification, and this only. And the Council firmly trust that the formation of a class of fellows, selected, in the first instance, for their character as accomplished surgeons, 
and its dignity maintained and perpetuated by the admission only of persons of higher education and extended experience, will, without fail, increase the estimation of surgeons generally, and no less of every member of the College.

In respect of the second question-viz., "Is the Council of the College disposed to admit to its board a fair representation of the members of the College in general practice?" The Council beg to remind the National Association that the College of Surgeons is not, and was never intended to be, a college of general practitioners, and that the members of the College, under whatever denomination, have no other recognised connexion with the College than as surgeons. The College of Surgeons is strictly an institution for the promotion of surgery, practical and scientific, and for testing the qualifications of those who intend to practise surgery. It is true that, under the existing arrangements of the medical profession in this country, the majority of its members are and will be general practitioners; it is true, also, that many of the provincial hospital surgeons, though practising the other branches of the profession, have eminently distinguished themselves by their scientific cultivation ( $f$ surgery, but it will scarcely be doubted that the greater number of those who conjoin with the practice of surgery that of medicine, pharmacy, and midwifery, from the multifarious vature of their pursuits, and from the unceasing demand upon their time and attention in their laborious and responsible avocations, will probably want the opportunities and inducements which are required for the special cultivation of surgery, and will scarcely be found to possess the qualifications for regulating the education of surgeons, and for promoting the great public objects for which the College was founded.

The third question-viz., "Would the Council of the College be willing to co-operate with the National Association of General Practitioners in the formation of a Court of Examiners in medicine, surgery, and midwifery," was probably intended to stand thus: Would the Council of the College be willing to cooperate with the proposed new corporation of general practitioners in the formation of a Court of Examiners in medicine, surgery, and midwifery? The Council, then, understanding this to be a proposal for forming a joint board of physicians, surgeons, obstetricians, and pharmaceutists, for the examination of general practitioners, have to express their readiness to submit to the enactments of the legislature, or to the regulations of the Council of Health, but they cannot but anticipate the inconvenience that would result from carrying on the examinations in anatomy, medicine, surgery, midwifery, and pharmace, at one board, and at one sitting, instead of distributing the subjects into distinct examinations; and they believe so protractud and multiform a demand upon the mind of the candidate would be calculated to perplex and bewilder even the best.informed student.

If, however, the aim of the Association be, when explicitly stated, that general practitioners are to be eligible to, or to constitute at all times a certain proportion of, the Court of Examiners of the College, the Council are bound to reply to the third as to the second question, and to state their unqualified conviction that the proposal for converting the College of Surgeons into a college of general practitioners, or depriving the College of its distinctive character and office, and of subsituting for these a medley of functions, each of which requires for its performance its dulyqualified functionaries, that the proposal of meroing the College of Surgeons into a college of practitioners in medicine, surgery, pharmacy, and midwifery, would defeat the very object for which the College was instituted, and would go tar to deprive the country of the best, and perhaps the only, mode of maintaining the efficiency of the surgical department of the profession. And if the class hitherto existing of teachers of anatomy and surgery is to be preserved-and the Council cannot believe that the Association has forgotten its paramount claims to public patronage and protection, -if the interest alike of the profession and country point out the necessity of fostering a class of men devoted to the absorbing pursuits of science. without whom, indeed, the very sources of professional knowledge would be dried up,-if adequate encouragement is to be given to the long, toilsome, and self-denying preparation for the offices of lecturers and surgeons of hospitals, uuder circumstances in which the prizes are few, and the rewards distant and uncertain, - it is scarcely too much to expect that the seats in the Council and in the Court of Examiners should be reserved for those whose habits and pursuits best fit them for the duties which an institution for the promotion of scientific surgery implies.

Lastly, with regard to the proposed incorporation of the general practitioners as a separate body or college, the Council have as little the wish as the power to prevent them from obtaining a charter, and would offer no objection to the incorporation of a body for the performance of the functions hitherto executed by the Society of Apothecaries; but, actuated as the Council are by the desire of promoting the usefulness and respectability of the general practitioners, they dare not, consistently with their sense of duty to the profession, and with their regard for the interests of the general practitioners themselves, hold out any hope of cooperation with the National Association in a plan for instituting a corporation which would supersede the defined and recognised functions of the existing College of Surgeons.

And they entreat the Association to bear in mind that by the provisions of the recent charter, and of the by-laws of the College in conformity therewith, the union of general practitioners with the College will in future be attained by means which cannot fail to raise their qualifications, and to promote their respectability. The fellow of the College who has obtained his degree at twenty-five years of age, after a liberal and extended education, will not be precluded from practising, in conjunction with surgery, the other branches of the profession; and a general practitioner, who may have been deprived of the opportunity of obtaining his degree at twenty-five, may become a fellow, after a definite number of years of practice.

That many, or all the members of the College will take advantage of these opportunities of honourable distinction is the sincere hope of the Council. And, in tendering their best wishes for the welfare and increased respectability of the general practitioners, they take leave to express their conviction that the claim which they fearlessly urge to disinterested motives, and a deep sense of their responsibility in the government of the College, will be cheerfully accorded in calner times by an enlightened pro. fession. - I have the honour to be, gentlemen,

Your most obedient servant,

Royal College of Surgeons of England, April 3, 1845 .

E. Belfour, Sec.

THE COLLEGE OF SURGEONS.-THE MEDICAL BILL. To the Honourable the House of Commons \&c.

The petition of the undersigned members of the Royal College of Surgeons of England residing in Wolverhampton,

Humbly Sheweth, -

That your petitioners have memorialized the Conncil of tije Royal College of Surgeons, in consequence of their partial and unjust appointments to the fellowship, hy the election of persons to that distinction who, by the test of our $\mathrm{Col}$ lege examination, are in no respect superior to ourselves, and, in many cases, are also our juniors; and that the Conncil, in reply to. your petitioners, have stated that they have no longer the power further to extend their appointments, and thus repair the injustice they have committed.

That your petitioners being thus grievously disappointed in obtaining that redress they had expected, approach your honourable house in the full confidence that some measure will be adopted of restoring to the members those privileges and surgical honours that they have been so unjustly deprived of by the acts of the Council.

That your petitioners humbly entreat that the Bill now pending before Parliament may not be permitted to become law till such an alteration has been effected in the present charter as will repair the injury your petitioners have sustained by annulling the degrading enactment, and so replacing them in that position they have so just a right to expect.

And your petitioners will ever pray.

MEMBERS OF THE COLLEGE OP SURGEONS.

\begin{tabular}{|c|c|}
\hline Date & of D \\
\hline William Wa & 1795 \\
\hline & \\
\hline hn Freese Proud, Consulting Surgeon to the Wolver- & 1804 \\
\hline 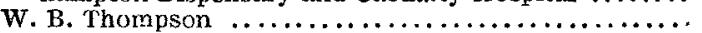 & 1809 \\
\hline lward H. Coleman & 1815 \\
\hline hn Dehane, M.D. & $18 \mathrm{I} 6$ \\
\hline John Steward & 1818 \\
\hline ancis Dehane, Surgeon to the Wolve & \\
\hline Dispensary and Casualty Hospital & 1827 \\
\hline Hiam & 1827 \\
\hline orge Edwardes & 1930 \\
\hline t Cartwright, Surge & \\
\hline d Casuaity Hospit & 1832 \\
\hline illam Quenton & 1834 \\
\hline Ir & 1842 \\
\hline mpson Cooper . & 1843 \\
\hline es C & 1843 \\
\hline iam & .1843 \\
\hline
\end{tabular}

\section{TONBRIDGE.}

ON Thursday, the 27th March, the General Medical Practitioners of the rural districts of the Western Division of the County of Kent, assembled at the Town Hall, Tonbridge, forthe purpose of taking into further consideration the Bill now pending in Parliament, entitled "A Bill for regulating the profession of 